\title{
O COTIDIANO DE TRABALHO DO AGENTE COMUNITÁRIO DE SAÚDE: ENTRE A DIFICULDADE E A POTÊNCIA
}

\author{
THE DAILY WORK OF THE COMMUNITY HEALTH AGENT: \\ BETWEEN DIFFICULTY AND POWER
}

EL TRABAJO DIARIO DE LO AGENTE COMUNITARIO DE SALUD: ENTRE LA DIFICULTAD Y POTENCIA

\author{
Deise Lisboa Riquinho ${ }^{1}$ \\ Tainã Vianna Pellini ${ }^{2}$ \\ Deise Taurino Ramos ${ }^{3}$ \\ Maicon Rodrigues Silveira ${ }^{4}$ \\ Vilma Constância Fioravante dos Santos ${ }^{5}$
}

Resumo O estudo objetivou analisar o processo de trabalho no cotidiano de agentes comunitários de saúde e as proposições de enfrentamento das adversidades comuns ao processo de trabalho no âmbito da Estratégia Saúde da Família de uma gerência distrital de saúde em Porto Alegre, Rio Grande do Sul. Tratou-se de estudo qualitativo com realização de grupos focais e entrevistas semiestruturadas, no período de agosto de 2015 a fevereiro de 2016. A análise ocorreu por meio de categorização temática. Os resultados emergiram a partir de quatro temas: o trabalho administrativo e a descaracterização do trabalho da agente comunitária de saúde; o cotidiano em equipe e suas condições de trabalho; as redes de atenção e sua descontinuidade no cuidado em saúde; e as táticas de enfrentamento entre as dificuldades e a potência. Ao se levarem em conta as interfaces entre o trabalho real e o prescrito, é inegável a necessidade de diálogo entre o controle social, profissionais e gestores para o enfrentamento das situações geradoras de sofrimento aos usuários e profissionais.

Palavras-chave agente comunitário de saúde; estratégia saúde da família; condições de trabalho.
Abstract This study aimed at analyzing the work process in the daily life of the community health agents and the strategies used to deal with the common adversities to the work process within the scope of the Family Health Strategies) of a District Health Management Center in the municipality of Porto Alegre, Rio Grande do Sul, Brazil. This is a qualitative study, carried out from August 2015 to February 2016, by means of focal groups and semi-structured interviews. The analysis of the data was done by thematic categorization. The results emerged from four main themes: Administrative work and the decharacterization of the Community Health Agents work; The daily life in a team and their working conditions; The attention networks and their discontinuity in health care; and Coping strategies between difficulties and potency. By considering the interfaces between actual and prescribed work of the community health agents, it is not possible to deny the need for dialogue between social control, professionals and managers to deal with situations that cause suffering to users and professionals.

Keywords community health agent; family health strategy; work conditions. 


\section{Introdução}

A Estratégia Saúde da Família (ESF) incorporou em sua essência a reorganização, a expansão e a consolidação da atenção básica no Brasil, desde a perspectiva teórica até a organização e implementação das políticas públicas que se voltaram para esse espaço de atenção em saúde. A ESF enfoca, prioritariamente, mudanças no processo de trabalho, das ações individuais para ações em equipe, ao considerar a interprofissionalização como uma forma de promover vínculo, cuidado longitudinal e mudança do modelo de atenção em saúde (Paim, 2003; Pinheiro e Silva Junior, 2009; Alves, 2005; Brasil, 2012).

Nesse contexto, o agente comunitário de saúde (ACS) insere-se como uma figura de destaque, tanto em relação à mudança do modelo assistencial quanto no que se refere ao engajamento para a constituição de um profissional que inter-relaciona saberes técnicos das equipes e saberes populares (Pinto e Fracolli, 2010). Esse trabalhador assume uma posição de mão dupla - morador da comunidade e, simultaneamente, integrante da equipe de saúde (Peres et al., 2011). O cuidado que se institui nessa relação está permeado pela maior percepção das necessidades e pela familiaridade com os costumes e cultura local. Ao se deparar cotidianamente com os limites da sua atuação, o ACS encontra-se inserido em um serviço que nem sempre tem condições de acolher as demandas que emergem do cotidiano vivido (Peres et al., 2011).

O duplo processo no qual se insere o ACS, na lógica institucional e comunitária em suas ações cotidianas, pode ser interpretado como o caminho necessário para estreitar as relações entre serviços de saúde e territórios. Tal raciocínio suscita a reflexão de como esse processo é conduzido, no sentido de incorporar o território no engendramento das políticas públicas, considerando que a forma de condução do processo de diálogo entre o local e a justaposição das políticas públicas interfere nos modos como transcorre a vida das pessoas e sua interação com os serviços de saúde (Lotta et al., 2012). Para o ACS, a duplicidade de ser morador local e representante de políticas públicas requer uma escuta constante e construção de vínculos afetivos ou, ainda, a sua interrupção e reconstrução com aqueles que são pares localmente - os moradores -, bem como a reprodução das diferentes concepções sobre o processo de produção do conhecimento e das políticas públicas, que se expressam nas ações institucionalizadas das equipes (Bornstein e Stotz, 2008).

Um olhar mais atento às formas como o trabalho do ACS se desenvolve cotidianamente sugere a perspectiva ergológica como uma possibilidade de análise do processo de trabalho e das estratégias de resistência desses profissionais a partir da realidade, o trabalho real. Sua operacionalização implica não apenas a execução das normas estabelecidas, mas uma permanente negociação entre estas, numa tendência à (re)normatização, resultante da singularidade das pessoas em relação ao coletivo (Schwartz, 2006). Assim, o trabalho real 
é o resultado da (re)normatização, e não a estrita aplicação e execução das normas, convocando um universo de microtransgressões, sendo ambiente propício para questionar o prescrito e o exercício de poder (Schwartz, 2006; Hennington, 2008).

$\mathrm{O}$ estudo que deu origem a este artigo teve por objetivo analisar o processo de trabalho no cotidiano dos agentes comunitários de saúde e as táticas de enfrentamento das adversidades comuns ao processo de trabalho no âmbito da Estratégia Saúde da Família de uma gerência distrital de saúde no município de Porto Alegre, no Rio Grande do Sul.

\section{Percurso metodológico}

Tratou-se de um estudo de abordagem qualitativa (Minayo, 2007), realizada em uma gerência distrital de saúde no município de Porto Alegre, Rio Grande do Sul. A população do estudo foram os ACSs das 28 equipes de ESF presentes no território, com a amostra composta de um agente por equipe. O critério de inclusão foi fazer parte do quadro funcional do serviço há pelo menos três meses, independentemente do vínculo empregatício; o de exclusão, estar afastado do trabalho no período da coleta de dados.

A geração dos dados ocorreu no período de agosto de 2015 a fevereiro de 2016, por meio de grupo focal e entrevista semiestruturada. Realizaram-se três grupos focais, com três encontros cada, totalizando nove encontros. As questões disparadoras para cada encontro foram: "pensando em seu trabalho, destaque as principais necessidades, os problemas sociais e de saúde das comunidades e territórios onde atua"; "como você, considerando determinado problema de saúde e seu contexto, desenvolve seu trabalho/orientação e ações de educação em saúde?"; e "em que medida os conhecimentos por você transmitidos provêm de suas experiências do cotidiano de vida e trabalho?" Participaram no primeiro grupo focal nove ACSs; no segundo, iniciaram nove ACSs, mas ocorreu a perda de duas participantes; no terceiro, iniciaram dez e houve uma perda, totalizando 25 participantes. Com estes, as entrevistas foram realizadas em suas respectivas ESFs, após agendamento prévio. As entrevistas enfocaram a quatros temas: trajetória de vida e aproximação com o ofício de ACS, o processo de trabalho e as redes de conhecimento. No estudo aqui apresentado, utilizaram-se os dados obtidos nos grupos focais e nas entrevistas semiestruturadas, especialmente no que se referia ao terceiro tema. O tratamento e a análise ocorreram por meio de categorização temática (Minayo, 2007). Para organização e auxílio na análise dos dados, utilizou-se o software Nvivo versão 10.

Em relação à caracterização dos sujeitos de pesquisa, a mediana de idade foi 45 anos. A maioria dos participantes era do sexo feminino ${ }^{6}$ (vinte mulheres). A autodeclaração da raça/cor apresentou o mesmo quantitativo de 
brancas e negras ( 11 , respectivamente) e três pardas. Quanto à escolaridade, 16 participantes tinham o ensino médio completo ou formação técnica; cinco delas, o ensino superior incompleto; três possuíam o ensino superior completo; e um havia completado o ensino fundamental. $\mathrm{O}$ vínculo empregatício das ACSs era via instituto municipal e hospital filantrópico, ambos submetidos à Consolidação das Leis do Trabalho (CLT). A mediana de tempo em exercício da profissão como ACS foi de dois anos (tempo mínimo de oito meses e máximo de 19 anos).

Para garantir o anonimato das participantes, as entrevistas foram identificadas pela letra A seguida de número arábico de 1 a 25; para o grupo focal, GF seguido do número do encontro (l a 3). O projeto de pesquisa foi submetido aos Comitês de Ética em Pesquisa da Universidade Federal do Rio Grande do Sul (UFRGS) e da Secretaria Municipal da Saúde de Porto Alegre, sendo aprovado por ambos, com o n. 1.009.554 e o n. 1.147.148, respectivamente.

\section{O trabalho das agentes comunitárias e o fazer na saúde: análise e discussão dos resultados}

Os resultados foram apresentados em quatro temas: o trabalho administrativo e a descaracterização do trabalho da ACS; o cotidiano em equipe e suas condições de trabalho; as redes de atenção e sua descontinuidade no cuidado em saúde; $\mathrm{e}$ as estratégias de enfrentamento, entre as dificuldades e a potência.

Ao rememorar a trajetória profissional em relação ao processo de trabalho, as ACSs enfatizaram que, no início da implantação da ESF, há aproximadamente vinte anos, suas principais atividades eram voltadas à promoção da saúde, envolvendo atividades individuais e coletivas. Ainda, destacaram a proximidade com as famílias proporcionada por essas atividades, como falou uma das ACSs durante um grupo focal: "era de sair para a rua, tu dares a cara para todo mundo ver" (Gl).

Durante os relatos, emergiu a consideração de que eram justamente essas atividades que lhes proporcionavam reconhecimento e respeito dos usuários. Em contraponto, atualmente, mencionaram que havia um distanciamento entre elas e as pessoas da comunidade, atribuindo isso às atividades que desenvolviam no interior dos serviços de saúde. A descrição dessas atividades ia desde atuar na recepção até realizar agendamento via sistema informatizado para consultas e exames de média e alta complexidades.

A permanência no interior da ESF, para as ACSs, tira o foco das atividades de acompanhamento dos grupos prioritários e famílias, havendo também o afastamento dos problemas locais, o que resulta na descaracterização não só do trabalho da ACS como também da própria ESF. Esse é um elemento que suscita discussões mais profundas; uma delas é a que emerge da consonância das características mencionadas pelas ACSs e pelas portarias n. 958 e n. 959, 
de maio de 2016, atualmente revogadas, mas que naquele momento abriram precedentes para que esses profissionais pudessem ser substituídos por técnicos de enfermagem (Brasil, 2016a, 2016b). A justificativa descrita em uma das portarias era a de que assim seria possível ampliar o foco na capacidade clínica na unidade de saúde e no domicílio pelas ESFs (Brasil, 2016a). Entretanto, a evidência que se obteve com a pesquisa indicou que, atualmente, há o deslocamento dos profissionais do foco do domicílio para dentro das ESFs em razão das atividades administrativas dos serviços. Dessa forma, formulase o seguinte questionamento: ampliar a força de trabalho com foco clínico é a melhor saída para as demandas que se têm hoje nos serviços de saúde? A figura da ACS como mediadora indica a necessidade de sua função para a implementação das políticas públicas ante a complexidade e a burocracia dos aparatos do Estado, de modo que é imprescindível a tradução que essas interlocutoras fazem com aqueles que ficam à margem de determinadas engrenagens (Lotta, 2015).

Segundo as ACSs, esse distanciamento da população culminou nas atividades de prevenção e promoção, dando lugar aos atendimentos emergenciais, por meio de situações de adoecimento agudizadas:

Em 15 anos, a gente nunca teve tantos bebês e tantas gestantes, diabético fora de controle, hipertenso fora de controle... Também, falta ACS, nós temos três, e aí, assim, AGOS7 acumulado, daí tem que digitar, é que eles querem números... A gente tem que dividir, parar... (A25).

As ACSs caracterizaram as atividades descritas como 'desvio de função', o que foi referido por boa parte das participantes da pesquisa. Como uma delas ilustrou, "só que infelizmente a gente está perdendo isso por causa dessa correnteza, dessa sobrecarga de trabalho que, na realidade, não é nosso e não nos compete" (GF3). Esta fala corrobora as considerações de Costa e colaboradores (2013), quando os pesquisadores declaram que o ACS se insere em um espaço de indeterminações e incertezas, sem definição clara de suas competências, habilidades e saberes. Os dados do estudo apontaram que essa indefinição pode estar abrindo precedentes para que elas assumam atividades que se distanciam de seu lócus de intervenção, o território vivido. Verificouse, com base nos depoimentos das interlocutoras, que atividades não prioritárias eram incorporadas e legitimadas no cotidiano, com uma tendência a tornar as atividades das ACSs um meio, e não ações finais para a qualificação e aproximação entre os serviços de saúde e a população. Segundo uma das entrevistas, "o agente tem que estar sempre lá, a gente tem que ser pau pra toda obra" (GF2). Outro aspecto que se somou às atividades consideradas como fora de seu escopo de atuação pelas agentes foi a introdução do e-SUS Atenção Básica (e-SUS AB), tema recorrente nas discussões coletivas. Havia 
um desagrado geral por parte dessas trabalhadoras com a necessidade de recadastrar os usuários e digitar as informações em computadores. Acerca do indicado, estudo realizado em Campinas, no estado de São Paulo, identificou que o menor desempenho de outras atividades no serviço não relacionadas ao núcleo de conhecimento do ACS ocorria devido à deficiência de recursos humanos e por desconhecimento da função desse profissional pelos demais, resultando na menor inserção desses trabalhadores na equipe (Nascimento e Correa, 2008). A reflexão suscitada diz respeito ao compartilhamento de responsabilidades entre os membros da equipe. O exemplo apontado pelas ACSs em relação ao e-SUS AB indica que é atribuição de toda a equipe alimentar o Sistema de Informação da Atenção Básica, registrando adequadamente as ações realizadas por meio de preenchimento manual ou digital das informações (Brasil, 2016c). É possível ainda refletir sobre o quanto as ESFs estão informadas sobre a importância desse sistema para o melhor funcionamento da atenção básica no Brasil. Essa é uma ação do Departamento de Atenção Básica para reestruturar suas informações em nível nacional, a qual está alinhada com a proposta mais geral de reestruturação dos Sistemas de Informação em Saúde do Ministério da Saúde (Brasil, 2016b).

As interlocutoras da pesquisa aqui apresentada apontaram que as atividades coletivas, como os grupos de educação em saúde, são cada vez menos organizadas ou mantidas nas ESFs, também se constatando a falta de qualificação e recursos para sua manutenção. Foi mencionada a inexistência de recursos, como data show para exibição de vídeos, bolas para a realização de atividades físicas e sala para encontros, entre outros materiais que ampliavam as possibilidades de intervenções pedagógicas pela equipe. Tal panorama acaba interferindo no sentido de que, mesmo havendo interesse em desenvolver atividades de educação em saúde com grupos específicos, como tabagistas, não se consegue, pois não há material de suporte. A falta de material de apoio pedagógico, bibliográfico ou audiovisual é um fator que impõe barreiras à prática educativa, porém não a impede de acontecer, uma vez que a prática educativa na ESF deve estar apoiada em um modelo social, imerso na cultura popular, a fim de sensibilizar as pessoas para a mudança no cuidado com a própria saúde (Vasconcelos, Grillo e Soares, 2009).

A prática empírica e a literatura alertam sobre a baixa participação das comunidades nas atividades educativas, bem como sobre sua escassez. Tais atividades, quando desenvolvidas, centram-se nas palestras e no uso de panfletos e imagens (Silva e Paula, 2016). Entende-se que as atividades em grupo visando à promoção da saúde na atenção básica se apresentam como uma alternativa às práticas assistenciais centradas no modelo de atenção vigente, o biomédico (Dias, Silveira e Witt, 2009; Cardoso et al., 2011). Portanto, superá-lo é um passo importante para a construção do sistema de saúde, pois 
este modelo historicamente substituiu o caráter relacional da atenção e cuidado em saúde pelas tecnologias diagnósticas (Pinheiro e Silva Junior, 2009).

\section{O cotidiano em equipe e suas condições de trabalho}

A atuação e o desempenho das ACSs estão ligados diretamente ao desenvolvimento das atividades em equipe, ou seja, dependem dos demais membros das ESFs. Entretanto, uma parcela significativa das interlocutoras mencionou dificuldades relacionadas ao trabalho em equipe. Para as agentes comunitárias, a falta desse entrosamento prejudica o andamento do serviço, resultando, muitas vezes, na insatisfação dos usuários, que não são atendidos em suas demandas. Elas também destacaram que, se o trabalho não for coeso, a articulação entre os membros da equipe fica fragilizada. Uma das ACSs mencionou: "o agente é feito um elo, mas uma corrente é feita de outros tantos elos" (GF2). Foi ressaltado, ainda, o individualismo dos profissionais - cada um preocupa-se com seu núcleo de atuação, sem ou com pouca interface com as atividades comuns a todos os membros da equipe.

Durante a realização dos grupos focais, foram externalizados sentimentos de frustração e desvalorização relacionados ao tratamento da equipe. Em suas percepções, ao mesmo tempo que lhes são depositadas expectativas de resolução para os problemas mais variados, faltam-lhes o reconhecimento e a valorização.

Qualquer coisa que acontece, "fala com a agente". Aí, quando tu queres falar: o que a agente comunitária quer falando?... Ao mesmo tempo em que uma agente comunitária vai salvar o mundo, ela não é ninguém (GF2).

A desvalorização da equipe em relação ao trabalho das ACSs pode estar vinculada com o saber informal que estas detêm; se os demais membros partirem da perspectiva de que o conhecimento científico pode refletir a realidade de forma fidedigna e mais adequada que o senso comum, o conhecimento acerca do cotidiano pode ser menos valorizado (Bornstein e Stotz, 2008). É nessa perspectiva que o trabalho do agente comunitário de saúde também acaba sendo desvalorizado.

A busca pela legitimação do saber das ACSs é trabalhada por meio da formação técnica oferecida pelo Sistema Único de Saúde (SUS), nos moldes do saber institucional, por meio das escolas técnicas do SUS (Etsus). No entanto, a oferta de formação está atrelada ao seu financiamento, não sendo assegurada a participação das três esferas de governo em sua totalidade; depende da aprovação e da garantia de financiamento pelos estados e municípios, o que gera descontinuidade em suas edições (Barros et al., 2010). 
A institucionalização, ou a sua necessidade imputada pelas políticas públicas que se voltam para esses profissionais, pode de certo modo reforçar a diferenciação dos saberes e dificultar ainda mais a possibilidade de aproximar, ou mesclar, os saberes que vêm do que é comum. A reflexão acerca do senso comum pode oferecer subsídios para a desvalorização das ACSs, no sentido de que seu conhecimento é comum, não por ser banal ou exterior, mas porque é conhecimento compartilhado entre os sujeitos da ação social (Martins, 2014). A desvalorização apontada também tem conexão com o fato de que a sobrecarga de trabalho não é acompanhada por um aumento da remuneração desses trabalhadores (Nunes et al., 2002).

Nessa perspectiva, é possível pensar sobre o reconhecimento atribuído à atenção básica. Como debatem Campos e colaboradores (2008), a cultura contemporânea valoriza mais o conhecimento do especialista do que o do generalista, com uma tendência a desvalorizar o trabalho desenvolvido na atenção básica, uma vez que este nível de atenção remeteria à noção de menor complexidade, àquilo que requereria menor qualificação técnica. Essa tendência se reflete na fala das ACSs sobre a postura dos usuários ao buscarem o serviço de saúde, de modo a reivindicar preferencialmente o atendimento médico, o que se traduz na resistência em aceitar a vinculação a outros profissionais e o acolhimento por eles.

As agentes comunitárias ressaltaram ainda que o controle social, por meio dos conselhos locais de saúde, legitima essa postura dos usuários - o que foi explicado por uma das interlocutoras ao ressaltar a inexistência de discussão com a comunidade sobre o funcionamento da ESF e as atribuições dos profissionais que a compõem. Tais atitudes estão relacionadas à influência do modelo biomédico hegemônico nas práticas em saúde. Apesar da existência de propostas e políticas que visam romper com esse paradigma, como a Política Nacional de Humanização (Brasil, 2004), as dificuldades para sua implementação ainda são significativas. As perspectivas teóricas e políticas de implementação de um novo modelo assistencial no Brasil são desafios que necessitam ser assimilados no cotidiano dos serviços de saúde por profissionais, equipes de saúde, usuários, suas instâncias de controle social e gestores da saúde (Fertonani et al., 2015).

As ACSs reconheceram que o número de profissionais nas ESFs está aquém da necessidade da população. Durante a realização do grupo focal, foi explicitado que, além das licenças e dos afastamentos por motivo de saúde ou demissão sem a reposição do trabalhador, era recorrente a transferência de médicos e enfermeiros para outras ESFs. Essa rotatividade de profissionais, segundo elas, dificulta o vínculo entre equipe e comunidade e produz uma sobrecarga de trabalho aos que permanecem. Duas entrevistadas ainda ponderaram que todo o seu trabalho de identificação das necessidades e de orientação dos 
usuários se perdia no momento em que estes procuravam a ESF e não eram atendidos por falta de profissionais.

Embora o vínculo longitudinal seja considerado um dos atributos mais importantes na ESF e esteja presente na prática diária dos profissionais que estão atuando, a rotatividade de profissionais, principalmente dos médicos e enfermeiros, compromete o vínculo das equipes com a comunidade e influencia negativamente o alcance dos resultados e a efetividade do modelo. Na análise de Stancato e Zilli (2010), foram destacadas como consequências da alta taxa de rotatividade no setor da saúde: a impossibilidade da manutenção das equipes integradas, a diminuição da produtividade devido ao tempo gasto com treinamentos repetidos, as dificuldades para novas contratações e a insegurança transmitida aos usuários.

O trabalho interprofissional deve ser um espaço de atuação compartilhada, indo além do campo de competências de cada membro da equipe e possibilitando a troca e complementaridade de saberes (Vasconcelos, Grillo e Soares, 2009). Apesar disso, as relações interpessoais são consideradas um desafio no aprimoramento do trabalho em equipe devido a diferenças de personalidade, interesses conflitantes e variadas concepções do que compõe o trabalho em equipe (Pereira, 2011). Conforme a pesquisa de Silveira, Sena e Oliveira (2011), identificou-se a dificuldade da equipe em conciliar as atividades da agenda programada com as demandas espontâneas. Mesmo reconhecendo a importância do trabalho em equipe, ocorria a fragmentação das tarefas no processo de trabalho, o que estava relacionado à sobrecarga de trabalho dos profissionais, ao número insuficiente de pessoal e ao excesso de demanda.

Outro aspecto explicitado pelas participantes da pesquisa foi que, diante desse cenário, a equipe de saúde, em muitas ocasiões, era agredida verbalmente. Os membros da ESF que atuam na linha de frente dos atendimentos e em constante contato com a população em diversos cenários assistenciais, os profissionais de enfermagem e as ACSs são justamente os mais vulneráveis às situações de violência, em comparação com o restante da equipe (Oliveira, Camargo e Iwamoto, 2013). As condições de trabalho constatadas pelas ACSs, como a insuficiência de espaço físico e de materiais considerados básicos, além de gerarem um ambiente inseguro aos trabalhadores e usuários, causam um desgaste cognitivo e afetivo para os trabalhadores que atuam com zelo no cuidado das famílias (Schwartz, 2010).

As entrevistadas apontaram para a quantidade insuficiente de computadores, a qualidade e a estabilidade da internet e do sistema, somadas ao fato de que a maioria afirmou não ter sido capacitada para tais atividades. Da mesma forma, houve outros relatos preocupantes quanto à escassez de materiais para curativos e medicação nas ESFs. Durante a realização da pesquisa, em algumas ESFs, a sala de vacina estava fechada por falta de imunobiológicos ou ainda pela ineficiência dos refrigeradores domésticos utilizados para conservá-los. 
Outro aspecto salientado foi o das más condições de infraestrutura, como falta de ventiladores e aparelhos de ar-condicionado, o que prejudicava o desempenho do atendimento em geral, além da constante falta de materiais de uso interno da ESF, como papel higiênico, papel-toalha e detergente, como se observou no seguinte relato: “Como que tu tratas da saúde, se tu não tens um princípio básico de higiene, de lavar uma mão e ter um papel, como que pode, não é?" (A10).

O trabalho da ACS está permeado pela complexidade e pelo desgaste emocional, que é mais evidente que nas demais classes profissionais do SUS, justamente pelo fato de ter uma inserção diferente: a de compartilhar uma rotina de vida com as pessoas e ao mesmo tempo ser trabalhador da saúde no local onde vive (Menegussi, Ogata e Rosalini, 2014). Segundo Jardim e Lancman (2009), essa dupla inserção na comunidade leva a ACS a desempenhar duplo papel - o de ser simultaneamente agente e sujeito -, não tendo distanciamento entre o ato de trabalhar e o de morar; por esse motivo, a forma como o trabalho está organizado pode ser uma fonte de sofrimento psíquico para esse trabalhador.

\section{As redes de atenção e sua descontinuidade no cuidado em saúde}

A organização do sistema de saúde foi um aspecto que sobressaiu nas falas das ACSs quando elas refletiram sobre seu processo de trabalho, especialmente sobre as dificuldades que enfrentavam em receber suporte às ações desenvolvidas na atenção básica. No que tange ao acesso aos serviços de saúde, atenção básica e média complexidade, as agentes relataram que a rede de serviços de saúde, ao longo dos anos, se tornou cada vez menos acessível, dificultando o encaminhamento dos usuários a consultas especializadas, farmácias e hospitais, o que, segundo elas, impede a continuação do cuidado à saúde da comunidade. As consultas com médicos especialistas foram citadas como um 'gargalo' do sistema de saúde, pois os usuários podem permanecer durante anos na 'fila', aguardando por um atendimento:

as pessoas ficam ali com uma demanda desde 2012/2013, daí tu vais lá, fazes todo um trabalho... Tem coisas que precisam pra ontem, e fica numa guerra com regulação, com gestores (GF1).

A comunicação entre os serviços que compõem a Rede de Atenção em Saúde (RAS) é um ponto tido como deficiente na perspectiva das ACSs. Da mesma forma como as consultas especializadas, o Núcleo de Apoio à Saúde da Família (Nasf) e o Centro de Referência de Assistência Social (Cras) são acionados com frequência, mas sem o retorno necessário para acompanhamento das situações que se impõem no cotidiano de trabalho. Segundo uma ACS, 
essa falha na comunicação entre os serviços de saúde dificulta o progresso dos casos, causando angústia nos profissionais envolvidos, que se sentem impotentes ante essas situações.

Uma situação vivenciada e compartilhada em um dos grupos focais foi um caso no qual diversos profissionais, como assistente social, psicólogo, enfermeiro e brigada militar estiveram envolvidos, mas a demora em sua resolução culminou na morte do usuário:

Ele só poderia ser internado por medidas do Ministério Público, ação compulsória, só que demora muito. E, pra resumir, isso acabou nem saindo, e ele já tinha morrido dentro de casa (A20).

Segundo as agentes de saúde, as situações que envolvem a saúde mental são bastante significativas; as pessoas ficam desamparadas pela falta de apoio e atuação intersetorial, que deveria proporcionar profissionais e serviços qualificados para esses casos. A equipe de ESF, na figura da ACS, está em contato direto e constante com a comunidade e tem capacidade de reconhecimento das necessidades em saúde no território, podendo favorecer a integralidade do acesso e vínculo ao serviço (Ayres et al., 2012). Contudo, ao longo do tempo, o modelo vigente organizou-se mais pelo modelo econômico do que pelas necessidades em saúde, em que a lógica é tratar a doença e não cuidar da saúde, resultando em um sistema médico-centrado e hospitalocêntrico, que funciona com base nos sintomas (Porto Alegre, 2013).

Ainda em relação ao processo de trabalho nos territórios e sua relação com a RAS, um apontamento inquietante que emergiu das falas foi a falta de sigilo de profissionais de outros setores e serviços nas denúncias realizadas, nesse caso os conselhos tutelares. As ACSs deparavam-se com situações complexas durante suas atividades na comunidade, como casos de violência de toda ordem, tais como agressões, abandono e abuso sexual. Um exemplo emergiu na discussão em grupo com as agentes quanto ao trabalho em conjunto com o conselho tutelar. Em determinadas situações, quando as denúncias partiam das ACSs, elas se sentiam vulneráveis a possíveis retaliações dos envolvidos na situação denunciada. Uma agente comunitária recordou uma situação em que seu esposo precisou intervir, pois ela foi ameaçada pelo provável agressor, e ainda casos em que a trabalhadora teve de mudar de endereço para manter sua integridade física e a da família.

Essas situações apontam para a delicada tarefa das ACSs, que, por serem representantes do Estado, devem atuar em defesa daqueles que não buscam por sua segurança, como no caso de algumas crianças ou idosos. Pari passu, por serem moradoras locais, também precisam de apoio para assegurar sua integridade. Todavia, a falta de segurança e o medo de sofrer ameaças estão relacionados à inibição de intervenções por parte dessas profissionais (An- 
drade et al., 2011). Também o medo e a insegurança para intervir com relação ao problema da violência podem contribuir para que essas situações se legitimem, uma vez que, por se sentirem expostas ao agressor, as trabalhadoras acabam agindo de maneira discreta e inespecífica, negando a atenção que deveria ser direcionada aos casos detectados e à prevenção de reincidência (Bezerra e Monteiro, 2012).

\section{As estratégias de enfrentamento, entre as dificuldades e a potência}

O enfrentamento das dificuldades encontradas no cotidiano do processo de trabalho das ACSs, especialmente vinculadas à sobrecarga e à descaracterização no trabalho, assim como a falta de materiais e estrutura deficiente, revelou, por um lado, formas potentes de cuidado e, por outro, um (des)cuidado com possibilidades de perpetuação de situações de violência e injustiças sociais. No cotidiano, as agentes comunitárias encontram maneiras criativas e solidárias para enfrentar as adversidades que se apresentam no trabalho desenvolvido, mas paradoxalmente há o silenciamento do sofrimento. A potência do trabalho do ACS é inegável, mas as dificuldades enfrentadas no cotidiano provocam sentimentos de desânimo e sobrecarregam a atuação do trabalhador (Speroni et al., 2016). A solidariedade entre as profissionais supre as capacitações insuficientes para as atividades de educação em saúde por meio do compartilhamento de conhecimentos e experiências entre os profissionais das ESFs. Enfatizou-se que cada um tem algum conhecimento, mesmo que equivocado, às vezes. Essa foi uma estratégia de colaboração utilizada por boa parte das participantes da pesquisa aqui apresentada, especialmente quando elas se viam diante de problemas sociais, num olhar mais amplo sobre o processo saúde e doença.

Em face da carência de materiais de consumo nas ESFs, as trabalhadoras relataram solicitar doações ou realizar compras com seus próprios recursos. Além disso, a exigência de utilizar os sistemas de informação para a digitação dos dados provenientes do trabalho das ACSs fez com que houvesse a necessidade de algumas adquirirem um computador para que seus filhos pudessem ajudá-las em casa. Entre as agentes, emergiram duas posições: aquelas que desenvolveram tolerância para lidar com tais atividades, executando-as diariamente; e aquelas que se negaram a executar outras atividades que não estivessem diretamente relacionadas com as pessoas da comunidade, como um posicionamento de resistência.

O trabalho em saúde não se resume à prescrição, definida a priori pelas organizações por meio de métodos e procedimentos, mas compreende situações concretas e suas vicissitudes (Brito, 2005). A complexidade dos problemas a serem resolvidos pelas ACSs no cotidiano foge ao escopo strictu da área da saúde, e as trabalhadoras relataram em suas falas que nem sempre era possível 
resolver os problemas das pessoas; contudo, o fato de disponibilizar momentos de atenção e escuta já seria um cuidado. Uma das falas das interlocutoras trouxe à tona a necessidade da escuta e da persistência na realização das ações cotidianas: "não precisa salvar o mundo, mas quem puder e, se for necessário, levar água com a mão, esse pouco para muita gente já é tudo" (GF3).

As considerações tecidas na fala remeteram ao conceito de mediação proposto por Gilberto Velho (2001), na compreensão de que todos têm contato com universos sociológicos, estilos de vida e distintos modos de percepção da realidade. Entretanto, certos indivíduos, mais do que outros, não só fazem o trânsito como também atuam como mediadores entre diferentes estilos de vida e experiências cotidianas. A ACS insere-se entre esses mediadores ao estar submersa em problemáticas que afetam a própria agente comunitária e seus familiares, como o acesso a bens e serviços de saúde. Do mesmo modo, insere-se na lógica institucional que, em razão da oferta de serviços limitada, nega direitos aos usuários. Como apontado pelas entrevistadas, conformar-se é uma forma de enfrentar os obstáculos relacionados à dificuldade de acesso: "tu acabas acostumando, porque ou tu acostumas, ou tu ficas frustrado e sai fora" (GF2).

Outro elemento do cotidiano que se situa na interface entre as dificuldades e a potência do trabalho das ACSs é morar e trabalhar na comunidade, cuja facilidade é atribuída à proximidade de casa e ao fato de não depender de transporte coletivo. Porém, também há dificuldades relacionadas a duas situações. Diferentemente dos demais profissionais, que em sua maioria, quando encerram o turno de trabalho, "pegam sua bolsa e vão embora", elas permanecem sendo solicitadas nas demandas de saúde e questionadas sobre a organização do serviço: “de manhã, às vezes, eles vão lá me chamar na minha janela"; e logo sugeriu: "deveria mudar, tinha que ser conosco trabalhando nas áreas de postos de outras áreas que não fossem a de nossa moradia" (GF2). A segunda situação diz respeito à privacidade dos usuários, que às vezes se surpreendem com a presença de alguém que eles conhecem desde a infância e visivelmente se mostram constrangidos e inseguros para prosseguir no atendimento, principalmente quando se trata de doenças transmissíveis.

A característica de as ACSs residirem no local de trabalho pode não facilitar o desenvolvimento de suas atividades, a ponto de serem reconhecidas como uma interferência negativa, de alguém que sabe muito sobre a comunidade e seus moradores (Menegussi, Ogata e Rosalini, 2014). Nas situações em que pode haver constrangimento por parte dos usuários em serem atendidos por alguém considerado por eles como um vizinho e não um profissional, a alternativa apontada para não se expor ou tomar conhecimento de informações delicadas ou sigilosas foi escolher uma ACS de outra área para atendê-los, uma vez que as ACSs normalmente são culpabilizadas quando informações sigilosas extrapolam o espaço do serviço de saúde e viram fofoca. 
Ser moradora no local em que se trabalha provocou, além dos constrangimentos, ameaça à segurança e à vida das agentes comunitárias. Por isso, elas apontaram a opção de não denunciar casos para o conselho tutelar ou mesmo de não os levar ao conhecimento da equipe:

Infelizmente, sabes quando tu queres resolver aquilo ali entre a equipe, pedindo ajuda do médico, do enfermeiro, psicólogo, chamar a família e fazer exames? Não dá. Hoje eu não levo nada mais proposto (GF3).

O receio dos profissionais de sofrer represálias do agressor ou de familiares das vítimas dificulta o processo de notificação ou denúncia. A falta de sigilo dos órgãos públicos que recebem a denúncia das situações de violência expõe as profissionais da ESF. Essa configuração representa um importante obstáculo, uma vez que a baixa credibilidade dessas instituições leva muitos profissionais a se omitirem diante da suspeita ou mesmo da revelação de violência e a apoiarem os agressores na manutenção do pacto de silêncio (Andrade et al., 2011).

\section{Considerações finais}

Estudar o processo de trabalho e as estratégias de enfrentamento no cotidiano de trabalho das ACSs reiterou as dificuldades enfrentadas pela expansão da atenção básica no Brasil, especialmente pelas precárias condições de infraestrutura, pelo desafio do trabalho em equipe na perspectiva da interprofissionalidade, com reconhecimento do quanto o cuidado em saúde pode ser composto por diferentes abordagens e saberes, e ainda pelo nó crítico das redes de atenção, com seus pontos enfraquecidos ou rompidos.

O papel desenvolvido pela ACS no desempenho de suas funções, em especial nas ações de educação e acompanhamentos das condições de saúde, tem sido questionado pelas próprias ACSs, na medida em que permanecem mais tempo no interior do serviço de saúde desenvolvendo atividades burocráticas, descaracterizando aquilo que entendem como o cerne de suas ações: estar em interação com o território. Além disso, há um constrangimento presente pelo fato de compartilhar o mesmo espaço como morador e trabalhador quando desenvolve suas atividades de mediar as políticas públicas e o cotidiano, evidenciando-se dúvida sobre a efetividade de morar e trabalhar no mesmo lugar, adequando-se ao plano normativo vigente. Esse constrangimento gera, inclusive, estratégias de (des)cuidado em relação aos agravos à população, como a omissão dos casos de violência para a equipe de saúde ou órgãos responsáveis.

Acredita-se na importância da consolidação da atenção básica no país por meio da priorização desse mecanismo de atenção à saúde, em uma retaguarda 
capaz de colaborar com sua resolutividade e na atuação dos diferentes segmentos sociais, dentre eles as ACSs, com a premissa de fortalecer os distintos saberes e necessidades presentes nos territórios. Ao se levarem em conta as confrontações do trabalho real e prescrito, é inegável a necessidade de diálogo entre as gestões locais do SUS, envolvendo controle social, profissionais e gestores para o enfrentamento das situações geradoras de sofrimento aos usuários e profissionais.

Espera-se que o estudo apresentado neste artigo lance olhares sobre o processo de trabalho da ACS em suas potencialidades e fragilidades, as quais se relacionam ao modelo de atenção em saúde, em exercício por meio da organização do sistema de saúde. Além disso, apontam-se questionamentos sobre a própria constituição do perfil profissional que se deseja para essas trabalhadoras, como residir no território onde trabalham, e também a necessidade de fomentar o debate entre profissionais e gestores, uma vez que as evidências revelaram discordância entre a função que os dispositivos da atenção básica deveriam desempenhar e a atuação das ACSs em colocar em prática atividades que moldam as principais características desse nível de atenção no sistema de saúde brasileiro.

Para os próximos estudos que venham a se debruçar sobre o tema, sugere-se que abarquem conjuntamente a percepção dos demais profissionais e gestores em saúde sobre o cotidiano de trabalho das ACSs, tendo em vista que as atividades dessas trabalhadoras deveriam viabilizar muitas políticas e programas em saúde nos municípios, os quais sofrem interferência das equipes e dos gestores.

\section{Colaboradores}

Deise Lisboa Riquinho e Tainã Vianna Pellini trabalharam em todas as etapas da pesquisa e da elaboração do artigo. Deise Taurino Ramos e Maicon Rodrigues Silveira participaram da coleta dos dados. Vilma Constância Fioravante dos Santos fez a revisão crítica. 
Resumen El objetivo de este estudio es analizar el proceso de trabajo cotidiano de los agentes comunitarios de la salud y su táctica de enfrentamiento de adversidades comunes a los procesos de trabajo en el ámbito de las Estrategias de Salud de Familia de una gerencia del distrito de salud del municipio de Porto Alegre, Rio Grande do Sul, Brasil. Se realizó un estudio cualitativo con creación de grupos focales y entrevistas semi-estructuradas, en el período agosto (2015)-febrero (2016). El análisis de los datos fue por categorización temática. Los resultados surgieron a partir de cuatro temas: el trabajo administrativo y la caracterización errónea de los trabajos de las agentes comunitarios de la salud; el equipo a diario y sus condiciones de trabajo; redes de atención y su discontinuidad en el cuidado de la salud; y estrategias de enfrentamiento entre las dificultades y la potencia. Al considerarse las interfaces entre el trabajo real y el prescrito, es evidente la necesidad del diálogo entre el control social, profesional y gestores para tratar las situaciones generadoras del sufrimiento a usuarios y profesionales.

Palabras clave agente comunitario de la salud; estrategia salud de la familia; condiciones de trabajo.

\section{Notas}

${ }^{1}$ Universidade Federal do Rio Grande do Sul, Escola de Enfermagem, Porto Alegre, Rio Grande do Sul, Brasil.

$<$ deise.riquinho@gmail.com>

Correspondência: Rua São Manoel, 963, sala 220, Santa Cecília, CEP 90620-110, Porto Alegre, Rio Grande do Sul, Brasil.

${ }^{2}$ Universidade Federal do Rio Grande do Sul, Porto Alegre, Rio Grande do Sul, Brasil. <vianna.taina@gmail.com>

${ }^{3}$ Universidade Federal do Rio Grande do Sul, Porto Alegre, Rio Grande do Sul, Brasil. $<$ deisetramos@gmail.com>

${ }^{4}$ Universidade Federal do Rio Grande do Sul, Porto Alegre, Rio Grande do Sul, Brasil. $<$ mikesilveira@gmail.com>

${ }^{5}$ Universidade Federal do Rio Grande do Sul, Porto Alegre, Rio Grande do Sul, Brasil. <vilmacfsantos@gmail.com>

${ }^{6}$ A maioria dos participantes do presente estudo era do sexo feminino: vinte mulheres. Por este motivo, neste manuscrito optou-se pelo emprego do gênero feminino na indicação desses trabalhadores.

${ }^{7}$ A entrevistada se refere ao Sistema de Regulação Ambulatorial Informatizada adotado pelo município de Porto Alegre (capital do estado, concentradora da capacidade instalada de serviços especializados de saúde) para os municípios do Rio Grande do Sul. 


\section{Referências}

ALVES, Vânia S. Um modelo de educação em saúde para o Programa Saúde da Família: pela integralidade da atenção e reorientação do modelo assistencial. Interface: Comunicação, Saúde e Educação, Botucatu, v. 9, n. 16, p. 39-52, 2005.

ANDRADE, Elisa M. et al. A visão dos profissionais de saúde em relação à violência doméstica contra crianças e adolescentes: um estudo qualitativo. Saúde e Sociedade, São Paulo, v. 30, n. 1, p. 147-155, 2011.

AYRES, José R. C. M. et al. Caminhos da integralidade: adolescentes e jovens na atenção primária à saúde. Interface: Comunicação, Saúde e Educação, Botucatu, v. 16, n. 40, p. $67-81,2012$.

BARROS, Daniele F. et al. O contexto da formação dos agentes comunitários de saúde no Brasil. Texto \& Contexto Enfermagem, Florianópolis, v. 19, n. 1, p. 78-84, 2010.

BEZERRA, Kelianny P.; MONTEIRO, Akemi I. Violência intrafamiliar contra a criança: intervenção de enfermeiros da Estratégia Saúde da Família. Revista da Rede de Enfermagem do Nordeste, Fortaleza, v. 2, n. 13, p. 354-364, 2012.

BORNSTEIN, Vera J.; STOTZ, Eduardo N. Concepções que integram a formação e o processo de trabalho dos agentes comunitários de saúde: uma revisão da literatura. Ciência \& Saúde Coletiva, Rio de Janeiro, v. 13, n. 1, p. 259-268, 2008.

BRASIL. HumanizaSUS: Política Nacional de Humanização - a humanização como eixo norteador das práticas de atenção e gestão em todas as instâncias do SUS. Brasília: Ministério da Saúde, 2004.

BRASIL. Politica Nacional de Atenção Básica. Brasília: Ministério da Saúde, 2012.

BRASIL. Portaria GM n. 958, de 10 de maio de 2016. Altera o Anexo I da portaria n. 2.488/GM/MS, de 21 de outubro de 2011, para ampliar as possibilidades de composição das equipes de atenção básica. Brasília: Ministério da Saúde, 2016a.

BRASIL. Portaria GM n. 959, de 10 de maio de 2016. Define o valor do incentivo de custeio referente ao acréscimo de profissionais na equipe multiprofissional: saúde da família. Brasília: Ministério da Saúde, 2016b.

BRASIL. Portal da Saúde. E-SUS atenção básica. Disponível em: <http://dab.saude. gov.br/portaldab/esus.php>. Acesso em: 6 jun. 2016c.

BRITO, Jussara. Trabalho e saúde coletiva: o ponto de vista da atividade e das relações de gênero. Ciência \& Saúde Coletiva, Rio de Janeiro, v. 10, n. 4, p. 879-890, 2005.

CAMPOS, Gastão W. S. et al. Reflexões sobre a atenção básica e a Estratégia de Saúde da Família: manual de práticas de atenção básica - saúde ampliada e compartilhada. São Paulo: Hucitec, 2008.

CARDOSO, Letícia S. et al. Finalidade do processo comunicacional das atividades em grupo na Estratégia Saúde da Família. Revista Latino-Americana de Enfermagem, Ribeirão Preto, v. 19, n. 2, p. 07 telas, 2011.

COSTA, Simone M. et al. Agente comunitário de saúde: elemento nuclear das ações em saúde. Ciência \& Saúde Coletiva, Rio de Janeiro, v. 18, n. 7, p. 2.147-2.156, 2013.

DIAS, Valesca P.; SILVEIRA, Denise T.; WITT, Regina R. Educação em saúde: o trabalho de grupos em atenção primária. Revista de APS, Juiz de Fora, v. 12, n. 2, p. 221-227, 2009.

FERTONANI, Hosanna P. et al. Modelo assistencial em saúde: conceitos e desafios para a atenção básica brasileira. Ciência \& Saúde Coletiva, Rio de Janeiro, v. 20, n. 6, p. 1.8691.878, 2015. 
HENNINGTON, Élida A. Gestão dos processos de trabalho e humanização em saúde: reflexões a partir da ergologia. Revista de Saúde Pública, São Paulo, v. 42, n. 3, p. 555-561, 2008.

JARDIM, Tatiana A.; LANCMAN, Selma. Aspectos subjetivos do morar e trabalhar na mesma comunidade: a realidade vivenciada pelo agente comunitário de saúde. Interface: Comunicação, Saúde e Educação, Botucatu, v. 13, n. 28, p. 123-135, 2009.

LOTTA, Gabriela S. et al. Saberes locais, mediação e cidadania: o caso dos agentes comunitários de saúde. Saúde e Sociedade, São Paulo, v. 21, p. 210-222, 2012.

LOTTA, Gabriela S.; VAZ, José C. Arranjos institucionais de políticas públicas: aprendizados a partir de casos do Brasil. Revista do Serviço Público, Brasília, v. 66, n. 2, p. 171-194, 2015

MARTINS, José S. Uma sociologia da vida cotidiana. São Paulo: Contexto, 2014.

MENEGUSSI, Juliana M.; OGATA, Márcia N.; ROSALINI, Maria H. P. O agente comunitário de saúde como morador, trabalhador e usuário em São Carlos, São Paulo. Trabalho, Educação e Saúde, Rio de Janeiro, v. 12, n. 1, p. $87-106,2014$

MINAYO, Maria C. S. O desafio do conhecimento: pesquisa qualitativa em saúde. 10. ed. São Paulo: Hucitec, 2007.

NASCIMENTO, Elizabet P. L.; CORREA, Carlos R. S. O agente comunitário de saúde: formação, inserção e práticas. Cadernos de Saúde Pública, Rio de Janeiro, v. 24, n. 6, p. 1.304- 1.313, 2008.

NUNES, Mônica O. et al. O agente comunitário de saúde: construção da identidade desse personagem híbrido e polifônico. Cadernos de Saúde Pública, Rio de Janeiro, v. 18, n. 6, p. 1.639-1.646, 2002.

OLIVEIRA, Lorena P.; CAMARGO, Fernanda C.; IWAMOTO, Helena H. Violência relacionada ao trabalho das equipes de saúde da família. Revista de Enfermagem e Atenção à Saúde, Cuiabá, v. 2, n. 2, p. 46-56, 2013.

PAIM, Jairnilson S. Epidemiologia e planejamento: a recomposição das práticas epidemiológicas na gestão do SUS. Ciência \& Saúde Coletiva, Rio de Janeiro, v. 8, n. 2, p. 557-567, 2003.

PEREIRA, Renata C. A. O trabalho multiprofissional na Estratégia Saúde da Família: estudo sobre modalidade de equipes. 2011. Dissertação (Mestrado em Ciências na área de Saúde Pública) - Escola Nacional de Saúde Pública Sergio Arouca, Fundação Oswaldo Cruz, Rio de Janeiro, 2011.

PERES, Cássia R. F. B. et al. O agente comunitário de saúde frente ao processo de trabalho em equipe: facilidades e dificuldades. Revista da Escola de Enfermagem da USP, São Paulo, v. 4, n. 45, p. 905-911, 2011.

PINHEIRO, Roseni; SILVA JUNIOR, Aluísio G. A centralidade do usuário na avaliação em saúde: outras abordagens. In: PINHEIRO, Roseni, MARTINS, Paulo H. (orgs.). Avaliação em saúde na perspectiva do usuário: abordagem multicêntrica. Rio de Janeiro: Cepesq/IMS/ Uerj; Recife: Editora Universitária UFPE; Rio de Janeiro: Abrasco, 2009. p. 37-52.

PINTO, Adriana A. M.; FRACOLLI, Lislaine A. O trabalho do agente comunitário de saúde na perspectiva da promoção da saúde: considerações práxicas. Revista Eletrônica de Enfermagem, São Paulo, v. 12, n. 4, p. 766-769, 2010.

PORTO ALEGRE. Prefeitura. Secretaria Municipal de Saúde. Plano Municipal de Saúde 20142017. 2013. Disponível em: <http://lproweb. procempa.com.br/pmpa/prefpoa/sms/usu_doc/ pms_2014_2017.pdf>. Acesso em: 5 jun. 2016.

SCHWARTZ, Yves. Entrevista. Trabalho, Educação e Saúde, Rio de Janeiro, v. 4, n. 2, p. 457-466, 2006.

SCHWARTZ, Yves. A experiência é formadora? Educação e Realidade, Porto Alegre, v. 35, n. 1, p. $35-48,2010$. 
SILVA, Marcela A. S.; PAULA, Maria A. B. Uso de recursos e estratégias pedagógicas na saúde da família. Revista de Ensino, Educação e Ciências Humanas, Londrina, v. 17, n. 2, p. 181-185, 2016.

SILVEIRA, Marilia R.; SENA, Roseni R.; OLIVEIRA, Suelen R. O processo de trabalho das equipes de saúde da família: implicação para a promoção da saúde. Revista Mineira de Enfermagem, Belo Horizonte, v. 15, n. 2, p. 196-201, 2011.

SPERONI, Katiane S et. al. Percepções dos agentes comunitários de saúde: contribuições para a gestão em saúde. Revista Cuidarte, Bucaramanga, Colombia, v. 7, n. 2, p. 1.3251.337, 2016.

STANCATO, Kátia; ZILLI, Priscila T. Fatores geradores da rotatividade dos profissionais de saúde: uma revisão de literatura. Revista de Administração em Saúde, São Paulo, v. 12, n. 47, p. 87-99, abr.-jun. 2010.

VASCONCELOS, Mara; GRILLO, Maria J. C.; SOARES, Sônia M. Práticas pedagógicas em atenção básica à saúde: tecnologias para abordagem ao indivíduo, família e comunidade. Belo Horizonte: Nescon/UFMG, 2009.

VELHO, Gilberto. Biografia, trajetória e mediação. In: VELHO, Gilberto; KUSCHNIR, Karina (orgs.). Mediação, cultura e politica. Rio de Janeiro: Aeroplano, 2001. p. 13-28.

Recebido em 08/09/2016. Aprovado em 17/02/2017. 
